\title{
Trends of streamflow, sediment load and their dynamic relations for the catchments in the middle reaches of the Yellow River in the past five decades
}

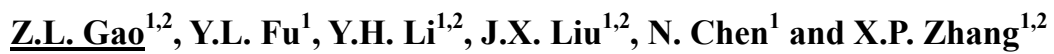 \\ 1. State Key Laboratory of Soil Erosion and Dryland Farming on the Loess Plateau,, Northwest A \& F \\ University, Yangling, Shaanxi 712100, China; 2. Institute of Soil and Water Conservation, Institute of Soil \\ and Water Conservation, CAS \& MWR Yangling, Shaanxi 712100, China \\ Email: gaozhl2004@126.com; zhangxp@ms.iswc.ac.cn.
}

\begin{abstract}
To control severe soil erosion on the Loess Plateau, China, a great number of soil conservation measures have been adopted since 1950s and subsequently, the "Grain for Green" project has been implemented from 1999. The measures and the project result in a large scale land use/cover change (LUCC). Understanding the impacts of the measures and the project on streamflow, sediment load and their dynamic relation is essential as the three elements are closely related to the sustainable catchment management strategy on the Loess Plateau. The data for seven selected catchments in the middle reaches of the Yellow River were used and standardized with precipitation and the controlling area for analysis. Nonparametric Mann-Kendall test and Pettitt test were employed to detect trends and change points of the annual streamflow and annual sediment load. Simple linear regressions for the monthly streamflow and sediment load from May to October were made to express their dynamic relation. Based on the change point identification and the time when the project began to implement on the Loess Plateau, the whole time for the data records was divided into three periods to compare the change extents in streamflow, sediment load and their dynamic relation between catchments.
\end{abstract}

Five out of the seven catchments, except the two loess hilly-gully catchments, had significant negative trends and change points for both the annual streamflow and annual sediment load. The change rate for streamflow in the three transition zone catchments was nearly 5 times that in the two rocky mountain catchments, which were -3.39 and $-0.67 \mathrm{~m}^{3} \cdot \mathrm{km}^{-2} \cdot \mathrm{mm}^{-1} \cdot \mathrm{a}^{-1}$, respectively. Correspondingly, the change rate for sediment load was nearly 10 times that, which were -0.5547 and $-0.054 \mathrm{t} . \mathrm{km}^{-2} \cdot \mathrm{mm}^{-1} \cdot \mathrm{a}^{-1}$, respectively. The change points for sediment load in the catchments occurred in the years from 1977 to 1982, which were considerably consistent with those for streamflow, especially in the three transition zone catchments. However, the change points detected in the transition zone catchments were earlier than those in the rocky mountain catchments. The relative changes at the high $(5 \%)$, median $(50 \%)$, and low $(95 \%)$ percentiles of time for both streamflow and sediment load represented by the monthly flow/sediment duration curves showed increasing trends with the shifted period. The change extents in sediment load were much greater than those in streamflow, especially in the three transition zone catchments.

The coefficients of the linear regression equations are found to be decreasing trends with the shifted periods in the six out of the seven catchments except Qingjian catchment. During the last 50 years, the adoption of soil conservation measures from 1970s to 1980s and the implementation of "Grain for Green" project after 1999 resulted in an average reduction of the sediment production coefficients by $22.4 \%$ and $63.4 \%$, respectively. The other two indices, the absolute value of a constant in the linear regression which can imply the sediment storage situation in a given period and the streamflow volume derived from the linear regression at which the catchment reaches a scour and silting balance, also show decreasing trends, especially in the transition zone catchments.

Results showed that in most of the cases, the decreasing change extents of streamflow, sediment load in the three transition zone catchments were greater than those in the two rocky mountain catchments. The effects of the LUCC on the three elements were much weaker in the two loess hilly-gully catchments. Response of sediment load to the LUCC in the catchments was much greater than that of streamflow, resulting in the statistically significant weakening trend in the dynamic relation.

Key words: Streamflow, Sediment load, Dynamic relation, Soil and water conservation, "Grain for Green" project, Catchment, Middle Reaches of Yellow River 
Gao et al, Trend of streamflow, sediment load and their dynamic relation in catchments on Loess Plateau.

\section{INTRODUCTION}

The Loess Plateau of $620,000 \mathrm{~km}^{2}$ is located in the middle reaches of the Yellow River $\left(750,000 \mathrm{~km}^{2}\right)$. It is characterized with heavily dissected landscape and severe soil loss resulted from wind-deposited loess soils, sparse vegetation, intense rainfall, and long agricultural history. To control the severe soil erosion, a number of soil conservation measures have been adopted on the Loess Plateau since the 1950s (Ye et al., 1994). The consequent land use and land cover changes dramatically altered hydrological regimes and significantly reduced sediment load in the Yellow River. However, it is not very clear how the soil conservation measures affect their dynamic relations in the catchment. Furthermore, the "Grain for Green" project has been widely implemented from 1999. It is important to fully understand the impacts of soil conservation measures and vegetation restoration on streamflow, sediment load, and runoff-sediment behaviors in the region.

It is well known that afforestation and other measures can alter catchment's water balance by increasing rainfall reception and evapotranspiration (Zhang et al., 2001). Soil erosion and sediment transport are therefore decreased through decreased surface runoff (Morgan, 1986; Castillo et al., 1997). Zhang et al. (2008) found that changes in streamflow tended to be relatively uniform across the flow spectrum with typical reductions of $30-60 \%$ in the catchments in the region due to soil conservation measures. A great number of researches showed that sediment load in the catchments on the Loess Plateau tended to have a significantly negative trend (Ye et al., 1994). Sediment load reductions across nearly entire spectrum were higher than streamflow (Fu, 2011). Runoff-sediment behaviors were also believed to change because of the mechanisms of afforestation and check dams. Xu et al. (2002) showed that the frequency of high concentration flow was decreased due to the implementation of soil conservation measures in the region. While the relation between streamflow and sediment load did not change essentially in the research of Pan et al. (1999) at a regional scale and even Zheng et al. (2007) in the small paired catchments. Rustomji et al. (2008) also showed that soil conservation measures seemly did not significantly change the sediment rating curves in two years with the similar precipitation in two catchments on the Loess Plateau.

Above studies indicate that land use/cover changes (LUCC) resulted from soil conservation measures can affect hydrological regimes and in turn, sediment transport processes. But the results are not consistent with the change of dynamic relation between streamflow and sediment load, probably due to different research scales, mixed natures of historic soil conservation measures, spatiotemporal distribution characteristics of streamflow and sediment load on the Loess Plateau. So, understanding the changes of streamflow and sediment load, and consequently their dynamic relation in the catchments on the Loess Plateau can provide an integrated estimate for the effects of soil conservation measures on hydrology and sediment transportation. Therefore, the specific objectives of this study were to (1) examine the trends and change points of annual streamflow and annual sediment load over the last 50 years in seven selected catchments on the Loess Plateau; (2) find the changes in the streamflow and sediment load represented by monthly flow/ sediment duration curves; and (3) investigate the changes of the relation between streamflow and sediment load in different periods in the catchments.

\section{STUDY AREA}

The $1.13 \times 10^{5} \mathrm{~km}^{2}$ coarse sand hilly catchments (CSHC) on the Loess Plateau are recognized as the main source of coarse sediment $(>0.1 \mathrm{~mm})$ on downstream bed. Average annual precipitation in the CSHC is 456 $\mathrm{mm}$ varying from more than $600 \mathrm{~mm}$ in the southeast to less than $300 \mathrm{~mm}$ in the northwest. About $78 \%$ of

Table 1. Description of the seven catchments in the middle reaches of Yellow River, China.

\begin{tabular}{|c|c|c|c|c|c|c|c|}
\hline Catchment & $\begin{array}{l}\text { Controlling } \\
\text { area }\left(\mathrm{km}^{2}\right)\end{array}$ & $\begin{array}{l}\text { Mean annual } \\
\text { precipitation } \\
(\mathrm{mm})\end{array}$ & $\begin{array}{l}\text { Mean annual } \\
\text { streamflow } \\
\left(10^{8} \mathrm{~m}^{3}\right) \\
\end{array}$ & $\begin{array}{l}\text { Mean annual } \\
\text { sediment load } \\
\left(10^{8} \mathrm{t}\right)\end{array}$ & $\begin{array}{l}\text { Vegetation } \\
\text { coverage }(\%)\end{array}$ & $\begin{array}{l}\text { Datum } \\
\text { Records }\end{array}$ & $\begin{array}{l}\text { Landform } \\
\text { feature }\end{array}$ \\
\hline Kuye & 8645 & 384.6 & 5.8 & 0.91 & 6.5 & 1956-2005 & \multirow{3}{*}{$\begin{array}{l}\text { Transition zone } \\
\text { from sandy } \\
\text { area to loess } \\
\text { hilly-gully area }\end{array}$} \\
\hline Tuwei & 3253 & 403.0 & 3.4 & 0.18 & 9.8 & $1956-2005$ & \\
\hline Jialu & 1121 & 412.0 & 0.6 & 0.13 & 3.3 & $1957-2005$ & \\
\hline Qingjian & 3468 & 477.7 & 1.4 & 0.40 & 3.6 & $1955-2005$ & \multirow{2}{*}{$\begin{array}{l}\text { Loess } \\
\text { hilly-gully area }\end{array}$} \\
\hline Yanhe & 5891 & 514.0 & 2.1 & 0.46 & 9.2 & 1956-2005 & \\
\hline Yunyan & 1662 & 541.0 & 0.3 & 0.03 & 54.7 & 1966-2005 & \multirow{2}{*}{$\begin{array}{l}\text { Rocky } \\
\text { mountain area }\end{array}$} \\
\hline Shiwang & 2141 & 561.0 & 0.7 & 0.02 & 66.5 & $1959-2005$ & \\
\hline
\end{tabular}

annual precipitation occurs from May to October. The northwestern part of the CSHC is considerably flat and the southeastern part is characterized by a heavily dissected landscape with gully densities ranging from 2 to 
Gao et al, Trend of streamflow, sediment load and their dynamic relation in catchments on Loess Plateau.

$8 \mathrm{~km} \cdot \mathrm{km}^{-2}$. The wind-deposited loess soils developed during Quaternary period cover the study area with a thickness of $50-200 \mathrm{~m}$. Coarse sandy soils are common in the northwest and finer clay-rich soils occur in the southeast(Ye et al.,1994).

Totally, seven catchments within the CSHC were selected for the purpose of the study, details of which are given in Table 1 . The seven catchments are located in three lanforms. Pasture is the dominant vegetation type in the three transition zone catchments and forest dominates the two rocky mountain catchments. In the two loess hilly-gully catchments, vegetation type is characterized with transitional features from steppe to forest.

The areas of terraces, afforestation, pasture land, and sediment-trapping dams all increased from 1959 to 1996. The rates of increase were greatest during 1970s and 1980s (Ran et al. 2000). The vegetation cover, represented by NDVI, was found to have an increasing trend at $P<0.05$ significance level on the Loess Plateau in last 20 years due to the "Grain for Green" project implementation (Xin et al., 2007).

\section{DATA AND METHODS}

\subsection{Data Description}

Monthly streamflow and sediment load data in the seven catchments were obtained from the Water Resources Committee of the Yellow River Conservancy Commission of China. Monthly precipitation data were obtained from the State Meteorology Bureau of China. Monthly precipitation data are spatially interpolated using ordinary Kriging method. An area-weighted method is used to compute the monthly precipitation in each catchment. Monthly streamflow, sediment load and precipitation data are then accumulated to annual totals. To reduce the effects of precipitation and drainage area on the analysis of the two elements between catchments, the volumes of annual/ monthly streamflow and sediment load are standardized by controlling area and the precipitation in corresponding time. So a unit for streamflow is " $\mathrm{m}^{3} \cdot \mathrm{km}^{-2} \cdot \mathrm{mm}^{-1}$ " and for sediment load, "t. $\mathrm{km}^{-2} \cdot \mathrm{mm}^{-1}$ ", which actually signify streamflow or sediment generation capability per unit area per unit precipitation in each catchments.

\subsection{Trend test and change point analysis}

Nonparametric Mann-Kendall method proposed by Mann (1945) and improved by Kendall (1975) is widely used to test trends in hydrological and climatological time series, mainly because it is simple, robust, and can handle the values missed or below the detection limits. The method has been recommended by the World Meteorological Organization (1988) as a standard procedure for detecting trends in hydrological data that are serially independent. Trend magnitude is estimated using a nonparametric median based slope method proposed by Sen (1968). Change point of the annual baseflow was tested by Pettitt approach (Pettitt, 1979).

\section{RESULTS AND DISCUSSION}

\subsection{Trends, Change Points and Changes in Hydrological Regimes for Streamflow}

Standardized annual streamflow in the five catchments except the two loess hilly-gully catchments presented negative trends at a statistically significance level by Mann-Kendall test. The rate of streamflow change was $-3.39 \mathrm{~m}^{3} \cdot \mathrm{km}^{-2} \cdot \mathrm{mm}^{-1} \cdot \mathrm{a}^{-1}$ in the three transition zone catchments, but only $-0.67 \mathrm{~m}^{3} \cdot \mathrm{km}^{-2} \cdot \mathrm{mm}^{-1} \cdot \mathrm{a}^{-1}$ in the two rocky mountain catchments. The average change rate for the former was about 5 times that for the latter. However, the two loess hilly-gully catchments, i.e., Qinjian and Yanhe catchments, were an exception. The change rate in Qinjian catchment presented a slightly increasing trend, but in Yanhe catchment, a slightly decreasing trend, both of which were statistically insignificant.

The annual streamflow in the five catchments had statistically significant change points. The change points for Kuye, Jialu, and Tuwei catchments in the transition zone occurred in 1981, 1982 and 1983 and for Yunyan, Shiwang catchments in the rocky mountain area, in 1988 and 1995, respectively. Clearly, years for the former were all earlier than those for the latter. The reason for such an occurrence is probably related to the time when the cumulative area of soil conservation measures in the catchments reached about $15 \%$. Result from Ran et al. (2000) indicates that such a percentage of soil conservation measures can significantly affect hydrological recycling in a catchment.

According to the change points for the five catchments and in consideration of the implementation of "Grain for Green" project after 1999, the whole time for the sequential streamflow data is divided into three periods: period 1 (pre-change point year, abbreviated to P1), period 2 (from the change point year to 1999, P2), and period 3 ("Grain for Green" period from 2000 to 2005, P3). Monthly flow duration curves were derived and 
Gao et al, Trend of streamflow, sediment load and their dynamic relation in catchments on Loess Plateau.

the relative changes of the streamflow in high(5\%), median(50\%) and low $(95 \%)$ percentiles of time in the periods 2 and 3 are listed in Table 2, as compared to the period 1.

Table 2. The relative changes in high, median, and low flow regimes in period 2 and 3 compared to the period 1 for the seven catchments.

\begin{tabular}{|c|c|c|c|c|c|c|c|c|c|c|c|c|c|c|}
\hline \multirow{2}{*}{ Catchment $^{\mathrm{a}}$} & \multicolumn{2}{|c|}{ Kuye $^{T}$} & \multicolumn{2}{|c|}{ Tuwei $^{\mathrm{T}}$} & \multicolumn{2}{|c|}{ Jialu $^{\mathrm{T}}$} & \multicolumn{2}{|c|}{ Qingjian $^{\mathrm{Lb}}$} & \multicolumn{2}{|c|}{ Yanhe $^{\mathrm{Lb}}$} & \multicolumn{2}{|c|}{ Yunyan $^{\mathrm{R}}$} & \multicolumn{2}{|c|}{ Shiwang $^{\mathrm{R}}$} \\
\hline & $\mathrm{P} 2$ & P3 & $\mathrm{P} 2$ & P3 & $\mathrm{P} 2$ & P3 & $\mathrm{P} 2$ & P3 & $\mathrm{P} 2$ & $\mathrm{P} 3$ & $\mathrm{P} 2$ & P3 & $\mathrm{P} 2$ & P3 \\
\hline$\Delta Q_{5}(\%)$ & -35.8 & -76.0 & -43.7 & -59.2 & -47.4 & -82.3 & -6.8 & -27.3 & -11.0 & -28.0 & -38.8 & -51.6 & -46.2 & -40.6 \\
\hline$\Delta Q_{50}(\%)$ & -43.6 & -65.7 & -23.3 & -40.3 & -42.3 & -69.2 & 13.8 & -15.8 & 13.0 & -17.3 & -28.4 & -44.2 & -37.8 & -52.3 \\
\hline$\Delta Q_{95}(\%)$ & -96.1 & -64.9 & -16.2 & -27.0 & -37.3 & -80.1 & -63.9 & 23.0 & 42.4 & 1.0 & -0.1 & -46.0 & -23.2 & -54.8 \\
\hline
\end{tabular}

Note: ${ }^{\text {a }}$, the superscripts in this row mean the locations of the study catchments. T means the transition zone from the sandy area to the loess hilly-gully area; L, the loess hilly-gully area; and R, the rocky mountain area. Some of following tables have the same marks.

, the change point years for Qingiian and Yanhe catchments are identified both in 1980 and 1999, refereed to other catchments.

From Table 2, the relative changes of streamflow were negative except for the two loess hilly-gully catchments, i. e. Qinjian and Yanhe catchments. The change extents, whenever in the period 2 and period 3, were higher in the three transition zone catchments than those in the two rocky mountain catchments.

The change extents of streamflow in the transition zone catchments were not only greater in the period 3 than those in the period 2, but also much greater than those in the rocky mountain catchments in the period 3 . The average relative changes for the three transition zone catchments in the period 3 reached $72.5 \%, 58.4 \%$, and $57.3 \%$ at the high, median, and low percentiles of time, respectively. Moreover, the average relative changes for the two rocky mountain catchments in the period 3 were $46.1 \%, 48.3 \%$, and $50.4 \%$ at the same percentiles, respectively. That means that the implementation of soil conservation measures had greater effects on the transition zone catchments than the rocky mountain catchments, especially in the period 3 when the "Grain for Green" project was implemented.

The change extents were much weaker for the two loess hilly-gully catchments, i.e. Qinjian and Yanhe catcments. The result is consistent with the trend detection for the five catchments.

\subsection{Trends, Change Points and Relative Changes for Sediment Load}

Like the annual streamflow, the annual sediment load in the five catchments except the two loess hilly-gully catchments had statistically significant decreasing trends and change points. The average change rate of the annual sediment load in the three transition zone catchments was $-0.5547 \mathrm{t} . \mathrm{km}^{-2} \cdot \mathrm{mm}^{-1} \cdot \mathrm{a}^{-1}$, and in the two rocky mountain catchments, only $-0.0540 \mathrm{t} \cdot \mathrm{km}^{-2} \cdot \mathrm{mm}^{-1} \cdot \mathrm{a}^{-1}$. Clearly, the change rate foe the former was nearly10 times the latter.

The change points of sediment load were also earlier in the three transition zone catchments, from 1977 to 1979. The change points in the two rocky mountain catchments were later, both in 1982 . The change points of the annual sediment load in the five catchments were close to those of the annual streamflow except Yunyan catchment, which implies that the effects of controlling erosion and sediment yield in these catchments are achieved through the surface runoff reduction by soil conservation measures. To investigate the relative changes in sediment load in the seven catchments, three periods are divided for in sediment load data based on the same period division criterion as for streamflow (Table 3).

Table 3. The relative changes in high (5\%), median (50\%), and low (95\%) of sediment load regimes in the P2 and $\mathrm{P} 3$ for the seven catchments, as compared to the P1.

\begin{tabular}{|c|c|c|c|c|c|c|c|c|c|c|c|c|c|c|}
\hline \multirow{2}{*}{ Catchment $^{\mathrm{a}}$, } & \multicolumn{2}{|c|}{ Kuye $^{T}$} & \multicolumn{2}{|c|}{ Tuwei $^{\mathrm{T}}$} & \multicolumn{2}{|c|}{ Jialu $^{\mathrm{T}}$} & \multicolumn{2}{|c|}{ Qingjian $^{\mathrm{Lb}}$} & \multicolumn{2}{|c|}{ Yanhe $^{\mathrm{Lb}}$} & \multicolumn{2}{|c|}{ Yunyan $^{\mathrm{R}}$} & \multicolumn{2}{|c|}{ Shiwang $^{\mathrm{R}}$} \\
\hline & P2 & P3 & $\mathrm{P} 2$ & P3 & $\mathrm{P} 2$ & P3 & $\mathrm{P} 2$ & P3 & $\mathrm{P} 2$ & P3 & $\mathrm{P} 2$ & P3 & $\mathrm{P} 2$ & P3 \\
\hline$\Delta S_{5}(\%)$ & -45.0 & -93.1 & -59.2 & -90.8 & -63.9 & -97.2 & -7.1 & -47.3 & -32.5 & -49.0 & -40.0 & -63.3 & -77.8 & -93.5 \\
\hline$\Delta S_{50}(\%)$ & -52.6 & -89.4 & -36.0 & -76.3 & -91.9 & -100 & -17.0 & -100 & -100 & -100 & - & - & - & - \\
\hline$\Delta S_{95}(\%)$ & -28.3 & -100 & -38.6 & -43.6 & - & - & - & - & - & - & - & - & - & - \\
\hline
\end{tabular}

Note: ${ }^{\text {a }}$, the mean of the superscripts in this row is the same with Table $2 .^{\text {b }}$, the change point years are identified in 1977 and 1999 both for Qingjian and Yanhe catchments.

Table 3 shows that compared to period 1, all the relative changes in the seven catchments are negative at the high, median, and low percentiles of sediment transport regime in the two latter periods. The increasing number of zero sediment load days in catchments is observed in the catchments including the two loess hilly-gully catchments.

For the three transition zone catchments, the average relative changes at the high $(5 \%)$, median $(50 \%)$ and low (95\%) sediment load in the period 2 were $56.0 \%, 60.2 \%$ and $33.5 \%$ and in the period $3,93.7 \%, 88.6 \%$ and $71.8 \%$, respectively. There were considerable differences in the relative change between the two periods. For the two rocky mountain catchments, the average relative change at high sediment load was $58.9 \%$ in the 
Gao et al, Trend of streamflow, sediment load and their dynamic relation in catchments on Loess Plateau.

period 2 and 78.4\% in the period 3. The result indicates significant effects of the soil conservation measures and "Grain for Green" project on sediment transportation in the study catchments. However, the effect of "Grain for Green" project implementation is much greater than that of soil conservation measures due to the continuity in the implementation process.

Compared to the streamflow, the change extents in sediment load, whatever the three flow/sediment load regimes and catchments are, are observed much greater.

\subsection{The Dynamic Relation between Streamflow and Sediment Load in the Catchments}

The change points of sediment load in the seven catchments are used to analyze the dynamic relation of streamflow to sediment load. Fig. 1 is a set of scatter diagrams illustrating relations of the monthly sediment load to the monthly streamflow in the three periods in the seven catchments with simple linear regression equations presented simultaneously. The monthly data of sediment load and streamflow used in this section are the values over the time from May to October.

Some equations in Figs.2b, 2c, and $2 \mathrm{~g}$, have poor correlative coefficients, which indicate that the sediment transport processes in the periods were largely influenced by human activities like soil and water conservation measures and the "Grain for Green" project implementation.

The domain of the scattered distributions of the monthly sediment load against the monthly streamflow in the three transition zone catchments is up to $\{1400,1000\}$, whereas in the two rocky mountain catchments, only $\{600,100\}$. Apparently, the former is much wider than the latter. The domain of the scattered distribution in the two loess hilly-gully catchments lies in the middle.
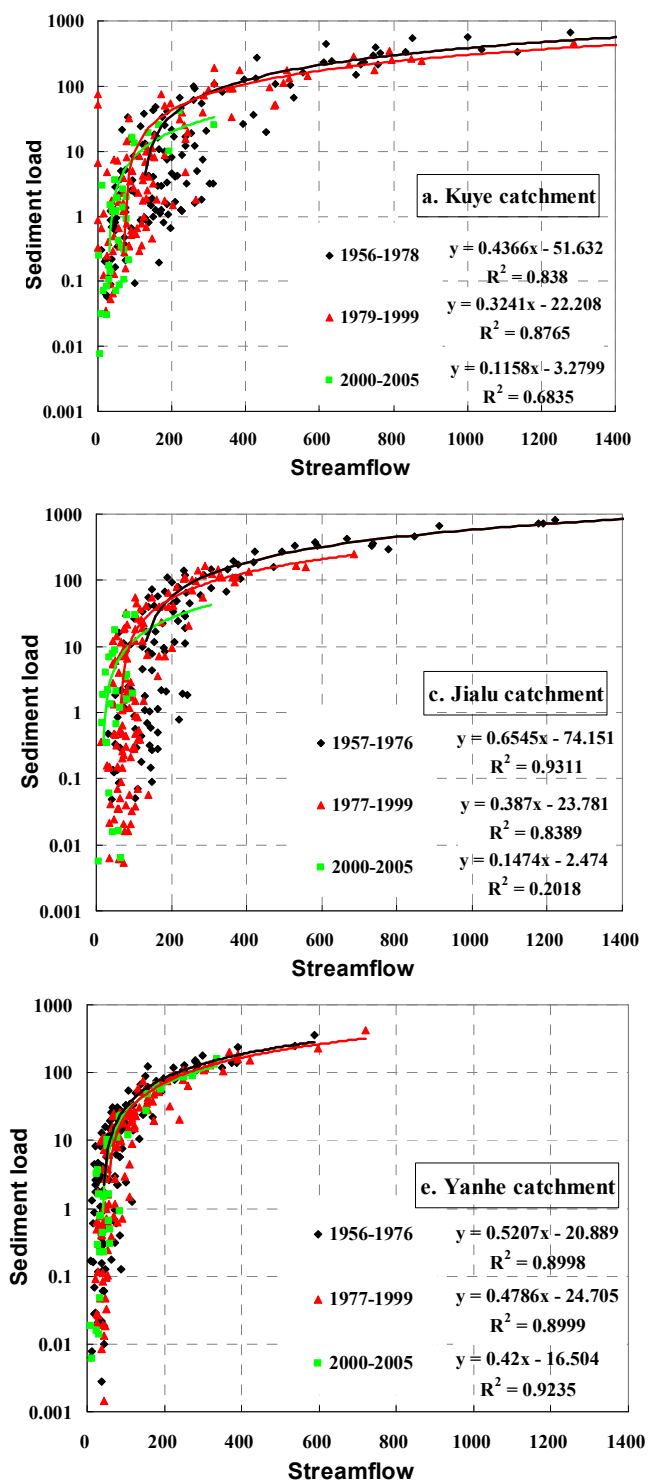
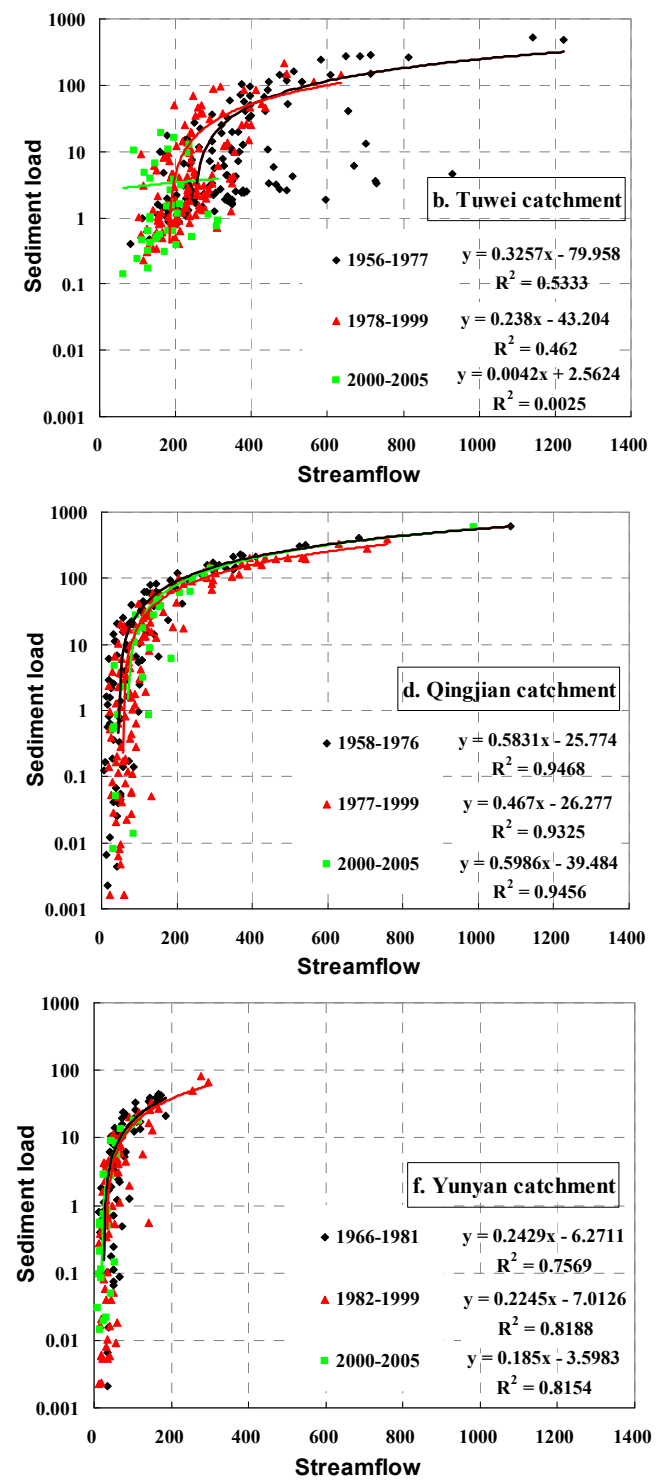
Gao et al, Trend of streamflow, sediment load and their dynamic relation in catchments on Loess Plateau.

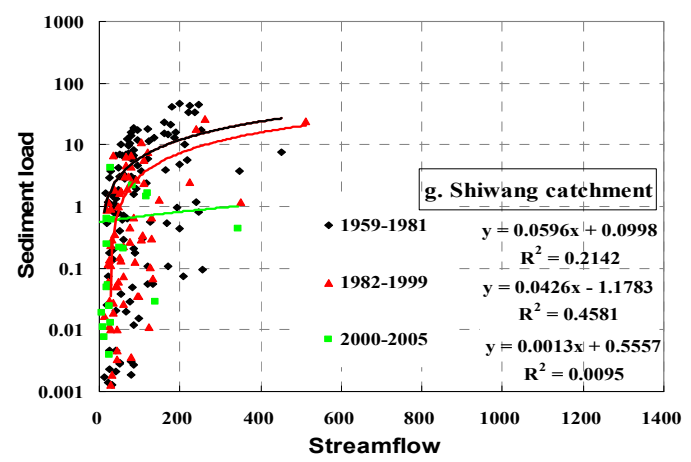

Figure 1. The scattered distributions and simple linear regressions for the monthly sediment load and monthly streamflow from May to October in the three periods in the seven catchments. It is normal in $\mathrm{X}$-axis and the $\log$ transition in $\mathrm{Y}$-axis. Plots $\mathrm{a}, \mathrm{b}$ and $\mathrm{c}$ in this figure represent the scattered distribution for the three transition zone catchments; plots d and e, for the two loess hilly-gully catchments; and plots f and $\mathrm{g}$, for the two rocky mountain catchments.

The regression coefficients can be considered as "sediment generation coefficients" because they may indicate the sediment generation capacity in the catchments. Fig. 1 shows that the linear regression coefficients, in general, are much higher in the transition zone catchments and the loess hilly-gully catchments than those in the rocky mountain catchments. The average coefficients in period 1, 2 and 3 are $0.4723,0.3164$ and 0.0891 in the three transition zone catchments and $0.5519,0.4728$ and 0.5093 in the two loess hilly-gully catchments, while they are only $0.1513,0.1336$ and 0.0932 in the two rocky mountain catchments. This indicates that with per unit of streamflow, the catchments located in the transition zone and loess hilly-gully area had a stronger capacity to generate and transport sediment than the catchments in the rocky mountain area. The reason is considerably related to the high vegetation cover in the rocky mountain area catchments, as shown in Table 1.

Table 4. Reduction of the linear regression coefficients for the monthly sediment load and streamflow in the catchments

\begin{tabular}{|c|c|c|}
\hline Catchment $^{\mathrm{a}}$ & $(\mathrm{P} 2-\mathrm{P} 1) / \mathrm{P} 1$ & $(\mathrm{P} 3-\mathrm{P} 1) / \mathrm{P} 1$ \\
\hline Kuye $^{T}$ & -25.8 & -73.5 \\
\hline Tuwei $^{\mathrm{T}}$ & -26.9 & -98.7 \\
\hline Jialu $^{\mathrm{T}}$ & -40.9 & -77.5 \\
\hline Qingjian $^{\mathrm{L}}$ & -19.9 & 2.7 \\
\hline Yanhe $^{\mathrm{L}}$ & -8.1 & -19.3 \\
\hline Yunyan $^{\mathrm{R}}$ & -7.6 & -23.8 \\
\hline Shiwang ${ }^{\mathrm{R}}$ & -28.5 & -97.8 \\
\hline Average & -22.4 & -63.4 \\
\hline
\end{tabular}

Both the adoption of soil conservation measures from the 1970s to 1980s and the implementation of "Grain for Green" project after 1999 made the sediment generation capacity in the catchments to be increasingly negative trends period by period, except the two loess hilly-gully catchments (Table 4). Compared to the period 1 , the average reduction rate of linear regression coefficients in the period 2 is $31.2 \%$ in the transition zone catchments and only $18.0 \%$ in the rocky mountain catchments, but in the period 3, it is up to $83.2 \%$ and $60.8 \%$, correspondingly. However, the negative trend is not evident in the loess hilly-gully catchments. The average reduction in the period 2 in all seven catchments is $22.4 \%$ and in the period 3, 63.4\% (Table 4).

In this study, the absolute value of a constant in the linear regression equation for each of the catchments implies the sediment storage situation in a given period. In the period 1, much more sediment was stored in the three transition zone catchments than in the two loess hilly-gully catchments and the two rocky mountain catchments (Fig.1). Correspondingly, the average constants are 68.6, 23.3 and 6.3, respectively. The sediment storage in the catchments showed a decreasing trend period by period except Qingjian catchment in the loess hilly-gully region. Compared to the period 1, the soil conservation measures from 1970s to 1980s made the sediment storage in the transition zone catchments and the rocky mountain catchments decreasing by $56.6 \%$ and $34.7 \%$ and the "Grain for Green" project implementation further decreasing by $95.8 \%$ and $42.6 \%$, respectively.

From the point view of equation, the streamflow volume at which sediment load equals zero may be understood as the situation in which a given catchment reaches its scour and silting balance (Fig.1). The standardized streamflow volume, at which the balance is needed for a catchment showed a decreasing trend with the shifted period in most of the catchments (Table 5). Especially in the three transition zone catchments, the average reduction of the streamflow volume, at which the balance needed, reached $38.0 \%$ in the period 2 and up to $80.6 \%$ in the period 3 .

Above all, the trends of three indices, i.e. regression equation coefficient, regression equation constant and 
Gao et al, Trend of streamflow, sediment load and their dynamic relation in catchments on Loess Plateau.

the streamflow volume at which a scour and silting balance reaches are found to be increasingly negative in most of the catchments. The decreased trends indicate that soil conservation measures and the "Grain for Green" project considerably weakened the sediment yield capacity and the dynamic relation of sediment load to streamflow in the study catchments.

\section{SUMMARY AND DISCUSSION}

This study examined the impacts of soil conservation measures and the subsequent "Grain for Green" project on streamflow, sediment load, and their dynamic relation for the seven catchments in the middle reaches of the Yellow River, China.

Results show that there are three types of responses in streamflow, sediment load, and their dynamic relations for the seven catchments. The effects of the LUCC on streamflow, sediment load, and their dynamic relation are greatest in the three transition zone catchments, with the two rocky mountain catchments followed. The effects are much weaker in the two loess hilly-gully catchments. In general, the change extents for sediment load are much greater than those for streamflow, which results in the increasingly weakening trends of statistical significance for the dynamic relation between the periods.

In considering of the standardization of the data by annual/monthly precipitation and catchment area, the decreasing/weakening trends of streamflow, sediment load, and their dynamic relation in the catchments were probably related to the characteristics of soil conservation measures adopted after 1950s. One was the total area controlled by soil conservation measures, by which the LUCC significantly affected hydrological recycling in a catchment. The other was the structure of soil conservation measures. It was the differences of landform and vegetation coverage that resulted in the intrinsic difference in the change extent between catchments. The responses of streamflow and sediment load to the LUCC in Qingjian and Yanhe catchments are different from those in other catchments, probably due to other kinds of human activities which could aggravate soil erosion and increase sediment transportation.

\section{ACKNOWLEDGEMENTS}

The work was supported by the National Natural Science Foundation of China (Grant No. 41101265) and the National Basic Research Program of China (973Program) (2007CB407203).

\section{REFERENCES}

Castillo, V.M., M. Martinez-Mena, and J. Albaladejo (1997). Runoff and soil loss response to vegetation removal in a semiarid environment. Soil Science Society of American Journal 61:1116-1121.

Kendall MG. Rank Correlation Measures. Charles Griffin: London. 1975.

Mann, H.B. (1945). Non-parametric tests against trend. Econometrica 13:245-259.

Morgan, R.P.C. (Eds.) (1986). Soil erosion and conservation. Longman Scientific and Technology. P:21-27,45-47.

Pan X.D., Li Y., Zhang X.H. (1999). The influence of the comprehensive treatment to streamflow and sediment load in the Hekou-Longmen region of Yellow River. Yellow River. 21(8): 13-15. (in Chinese).

Pettitt, A. (1979). A nonparametric approach to the change-point problem. Applied Statistics 28: 126-135.

Ran D.C., Liu L.W., Zhao L.Y. et al eds. (2000). The soil conservation practices and streamflow and sediment load changes in the Hekou-Longmen region of middle reaches of Yellow River. Zhengzhou: Yellow River Water Conservancy Press. (in Chinese).

Rustomji P., X.P. Zhang.P.B. Hairsinen, L.Zhang, and J.Zhao (2008), River sediment load and concentration responses to changes in hydrology and catchment management in the Loess Plateau region of China. Water Resources Research, 44, W00A04, doi:10.1029/3008WRR006656.

Sen PK. 1968. Estimates of the regression coefficient based on Kendall's tau. Journal of the American Statistical Association 39: 1379-1389.

Xin Z B, Xu J X, Zheng W. Response of vegetation cover change to climate change and human activities in Loess Plateau. Science in China: Series D, 2007, 37 (11):1504-1514. (in Chinese).

$\mathrm{Xu}$, J.X. (2002). The impacts of human activity on hyperconcentrated flow in the middle reaches of Yellow River. Scientia Geographica Sinica. (3): 294-299. (in Chinese).

Ye Q.C. (1994) eds. Researches on environemtnal changes of the Yellow River Basin and laws of water and sediment transportation. Jinan: Shandong Science and Technology Press. (in Chinese).

Zhang L., Dawes W., Walker G. (2001). Response of mean annual evapotranspiration to vegetation changes at catchment scale. Water Resource Research 37:701-708

Zhang X.P., Zhang L., Zhao J., Rustomji P., and Hairsine P. (2008). Responses of streamflow to changes in climate and land use/cover change in Loess Plateau, China, Water Resour. Res., 44, W00A07, doi:10.1029/2007WR006711.

Zheng M.G.,Cai Q.G.,(2007). Effects of vegetation and other measures for soil and water conservation on runoff-sediment realtionship in watershed scale. Jounal of Water Conservancy,38(1): 47-53. (in Chinese). 